\title{
Incoherent Scatter Radar Observations of Westward Electric Fields, 2
}

\author{
C. L. RINO AND V. B. WICKWAR \\ Stanford Research Institute, Menlo Park, California 94025
}

\author{
P. M. Banks \\ Department of Applied Physics and Information Science, University of California, San Diego, La Jolla, California 92037
}

\author{
S.-I. AKasofu AND E. Rieger'
}

Geophysical Institute, University of Alaska, College, Alaska 99071

\begin{abstract}
In this paper we describe the results of a series of geomagnetic meridian plane radar incoherent scatter plasma transport measurements. From such data the eastward (zonal) component of the electric field can be deduced. The results show that the electric field has an eastward component whenever the discrete auroras are northward of the region of the measurement. The zonal field component turns westward as the discrete auroras move equatorward of the region of the measurement. Thus there is an eastward electric field boundary near the equatorward limit of the discrete aurora, which is the poleward boundary of the diffuse aurora during undisturbed periods. During a particularly disturbed period we also observed three pronounced substorm-related enhancements of the westward-directed zonal field. For midnight and morning sector substorms the enhancements preceded the substorm onset times by $20-30 \mathrm{~min}$. We show from meridian chain all-sky camera data that all three enhancements coincided with equatorward expansions of the auroral oval.
\end{abstract}

In spite of a great need in interpreting various magnetospheric and ionospheric phenomena it is only during the last several years that reliable measurements of electric fields have become available. In particular, since large-scale convective motion of magnetospheric plasma is one of the most important processes in the magnetosphere, it is important to examine how it varies during magnetospheric substorms. In this paper we shall describe ground-based observations of the ionospheric meridional component of this convection, or equivalently the east-west electric field component.

In a recent review paper, Vasyliunas and Wolf [1973] pointed out that although there is agreement on the general features of the north-south component of the electric field, there is confusion as to both the nature and the significance of the east-west component. In the midnight sector a westward electric field component drives the magnetospheric plasma in the tail region radially inward toward the earth, and this activity ultimately results in a change of the geomagnetic field configuration from 'taillike' to 'dipolelike' [Mozer, 1971; McPherron et al., 1973]. This action often precedes magnetic substorms; it has been associated with a substorm growth phase by Coroniti and Kennel [1972].

Our data are derived from a series of magnetic meridian plane drift measurements made with the Chatanika, Alaska ( $L=5.7^{\circ}, \Lambda=65.2^{\circ}$ ), auroral zone incoherent scatter radar. The incoherent scatter radar data can be processed to obtain the line-of-sight component of the plasma ion drift. Thus above altitudes where atmospheric drag is significant one can determine the corresponding component of the convection electric field $\mathrm{E}_{c}=-\mathrm{V} \times \mathrm{B}$, which can be taken as a defining relation.

\footnotetext{
${ }^{1}$ On leave from Max-Planck-Institut für Extraterrestrische Physik, Munich, Germany.

Copyright (c) 1974 by the American Geophysical Union.
}

When the measurements are confined to the plane of the magnetic meridian, the data are sensitive only to the eastward component of $\mathrm{E}_{c}$, which we shall designate as $E_{E}$. However, parallel drifts also contribute to the meridian plane data. When the transverse drift is large, say, greater than $300 \mathrm{~m} / \mathrm{s}$, it has been found that the parallel component is generally negligible. A detailed discussion is given in the paper by Banks et al. [1974] (hereafter paper 1), in which an earlier set of magnetic meridian plane measurements is presented.

An important result of the study presented in paper 1 was the observation of patches of ionization moving southward at the same speed as the convective drift seen in adjacent regions of lower-electron density. Within the moving patch, however, the observed east-west component of the electric field was small. Throughout the measurement period, equatorward plasma transport was observed, but owing to the high level of magnetospheric disturbance, it was not possible to deduce any definite substorm relationships.

The data that we shall present in this paper support the following general results concerning the nature of the eastward component of the convection electric field.

1. When measurements are made equatorward of the instantaneous auroral oval as defined by Snyder and Akasofu [1972], $E_{E}$ is positive; that is, there is a poleward convection component.

2. When measurements are made within the instantaneous auroral oval as indicated by the presence of discrete auroras equatorward of the measurement, $E_{c}$ is negative; that is, there is an equatorward convection component.

3. During a 10-hour series of measurements made on February 24, 1973, three pronounced enhancements of the westward-directed electric field component were seen. Each enhancement was coincident with an equatorward expansion of the instantaneous auroral oval. Moreover, the enhancements that occurred during the midnight and morning time sectors preceded major auroral substorms. 
4. An anticorrelation of $E_{E}$ with the presence of bright active auroral forms at the 'foot' of the measurement flux tube has been observed. We have interpreted this phenomenon as a manifestation of electric field shorting by local precipitationinduced conductivity enhancements as described by Mozer et al. [1973]. This effect was observed more directly in the data presented in paper 1 as a signal strength-electric field anticorrelation. In the data reported in this paper the signal levels were generally weaker, so that a direct comparison was inconclusive.

\section{RESUlts FOR FEBRUARY 24, 1973}

\section{Radar Observations}

On February 24, 1973, a 10-hour series of measurements was made with the Chatanika incoherent scatter radar. The data were recorded with the antenna elevation angle fixed at $45^{\circ}$ at a true azimuth of $29^{\circ}$, the magnetic declination angle at Chatanika. The electric field component $E_{E}$ was computed from the ion drifts measured with a $48-\mathrm{km}$ range gate centered at $167 \mathrm{~km}$ as discussed in paper 1 .

In Figure 1 the College, Alaska, magnetometer data are shown together with the radar measurements of $E_{E}$. For this first presentation, a 5-min integration was used for each data point. The general features are that $E_{E}$ was eastward-directed (positive) from the beginning of the measurement until just before 0700 UT when it turned westward (negative). It remained westward-directed throughout the evening until approximately 1330 UT. (We note that Alaska standard time (AST) is UT minus 10 hours.)

Superimposed on this general pattern are three distinct enhancements of $E_{E}$ commencing at $\sim 0700$ UT, $\sim 0930 \mathrm{UT}$, and $\sim 1300$ UT. These will be referred to as the evening, midnight, and morning sector enhancements, respectively. The evening sector enhancement is clearly associated with the College magnetometer variations that occurred between 0700 and $0800 \mathrm{UT}$. The pattern of these magnetometer variations is evidence of an intense surge passing over College, Alaska. This point is discussed further in the section on auroral observations.

The midnight sector enhancement coincided with the gradual development of a negative $H$ bay at $\sim 0940$ UT. However, this enhancement had subsided by the time of the abrupt deepening of the $\boldsymbol{H}$ component negative bay at $\sim 1015$ UT. The morning sector enhancement coincided with a large westward excursion of the College magnetometer $D$ component.

In Figure 2 we show the same radar data processed with 1min integration together with the magnetometer $H$ component recording from Sitka $(L=3.91)$, Meanook $(L=4.66)$, and College $(L=5.4)$. Since our expected statistical uncertainty is of the order of $5 \mathrm{mV} / \mathrm{m}$ (paper 1), the large, rapid excursions in the data are true characteristics of the electric field.

At $0700 \mathrm{UT}$, Meanook is a midnight sector station while College is an evening sector station. Sitka falls roughly halfway in between. Indeed the Meanook negative $H$ bay beginning at $\sim 0630$ is strikingly similar to the College negative $H$ bay beginning at $\sim 0940$ when that station is in the midnight sector. The available Russian magnetometer records from Dixon and Tixie Bay that are near the midnight sector at 1300 UT were less definitive.

Evidently, there were three major polar magnetic substorms; the first near 0700 UT and the second near 1000 UT. The third, which was not so well defined, occurred near 1300 UT. However, from such magnetometer data alone, a precise identification of the substorm onset times cannot be made. For example, Does one choose the beginning of the negative bay onset in the midnight sector or the time of its most rapid increase? (Compare Meanook at 0640 and 0700 UT and College at 0940 and 1015 UT.) To resolve these ambiguities, we have utilized all-sky camera data from the Alaska meridian chain of stations located at College, Fort Yukon, Inuvik, and Sachs Harbor.

The meridian chain data give a latitudinal cross section of the aurora at a fixed geomagnetic longitude as a function of time. Thus one obtains the distribution of auroras with a high resolution in latitude and time but with limited global coverage. The technique of analyzing such data is discussed in detail by Snyder and Akasofu [1972].

\section{Auroral Observations}

In Figures $3 a$ and $3 b$ the auroral patterns observed along the

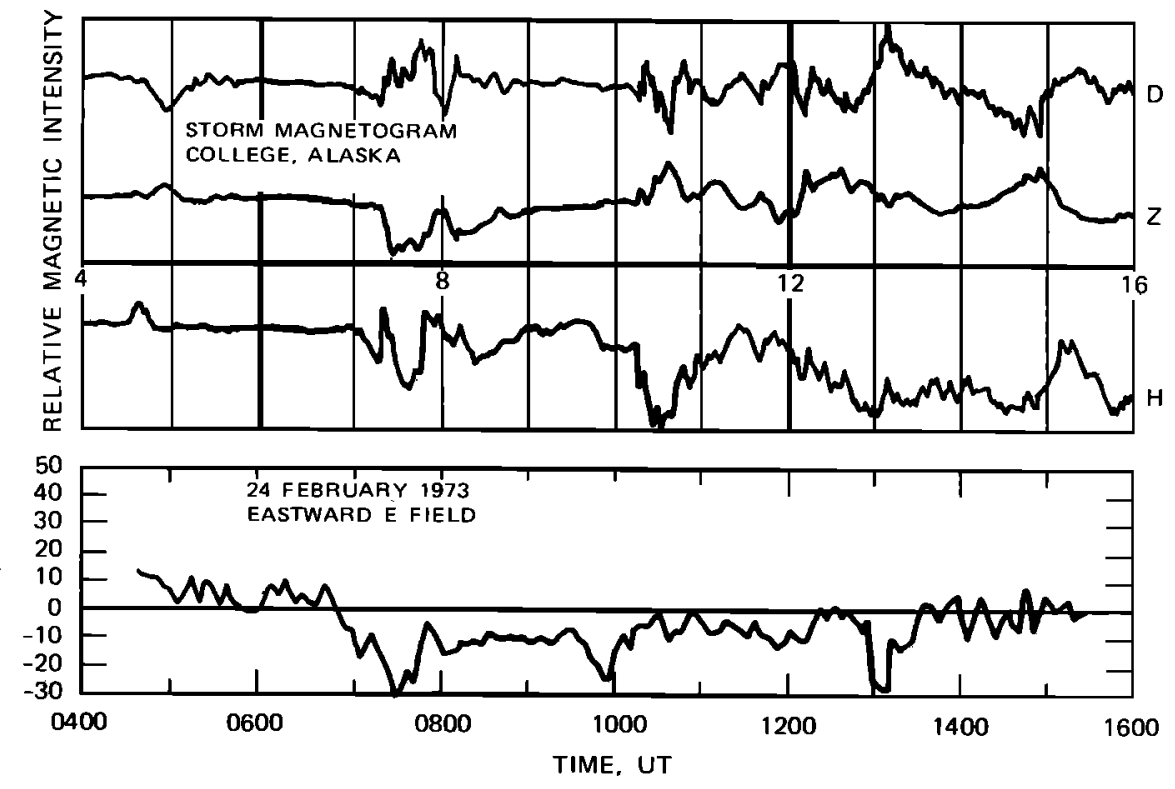

Fig. 1. Summary of meridian plane measurements for February 24, 1973, experiment. 
Rino et al.: Radar Observations of Westward Electric Fieliss, 2
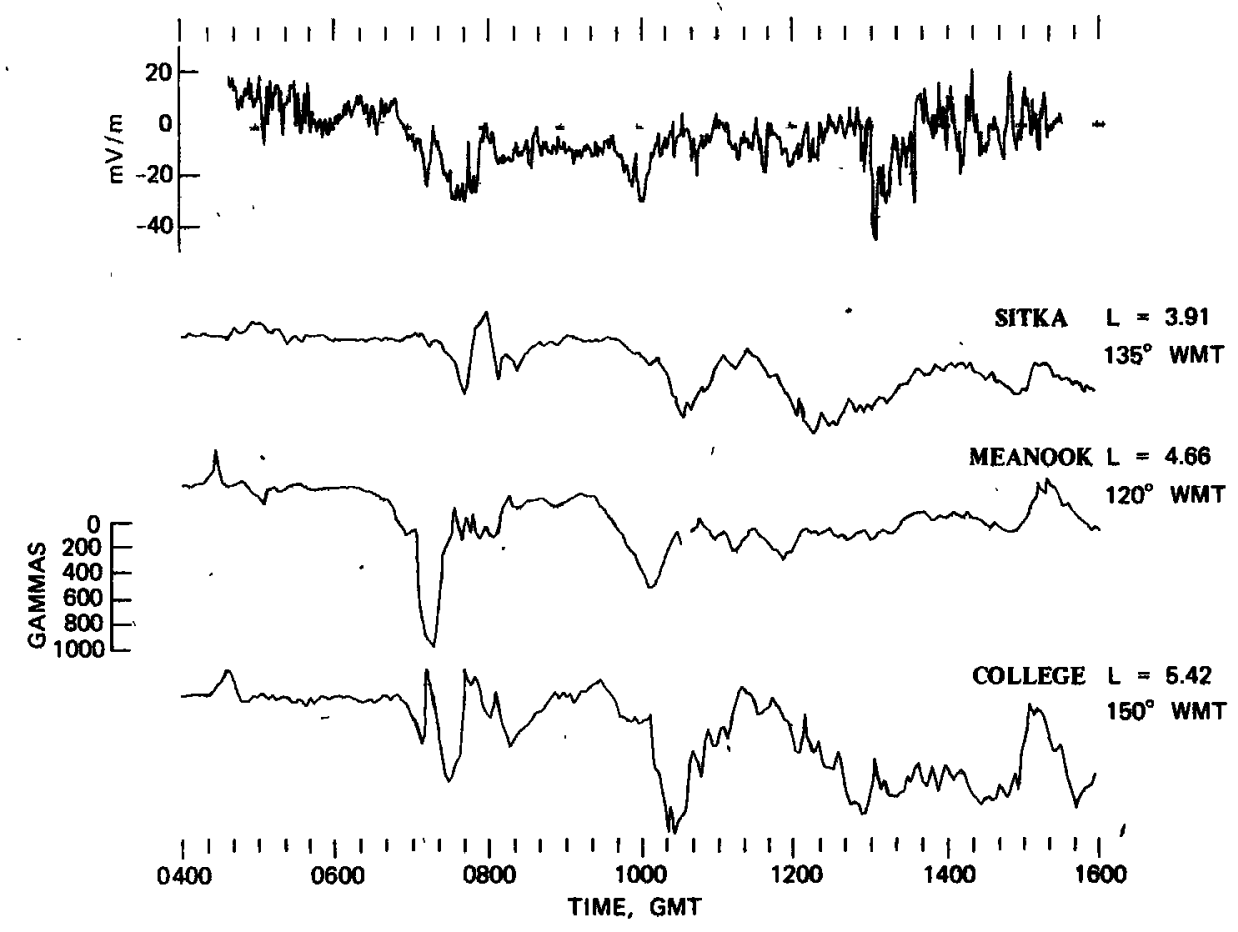

Fig. 2. Simultaneous radar and magnetometer $H$ component records.

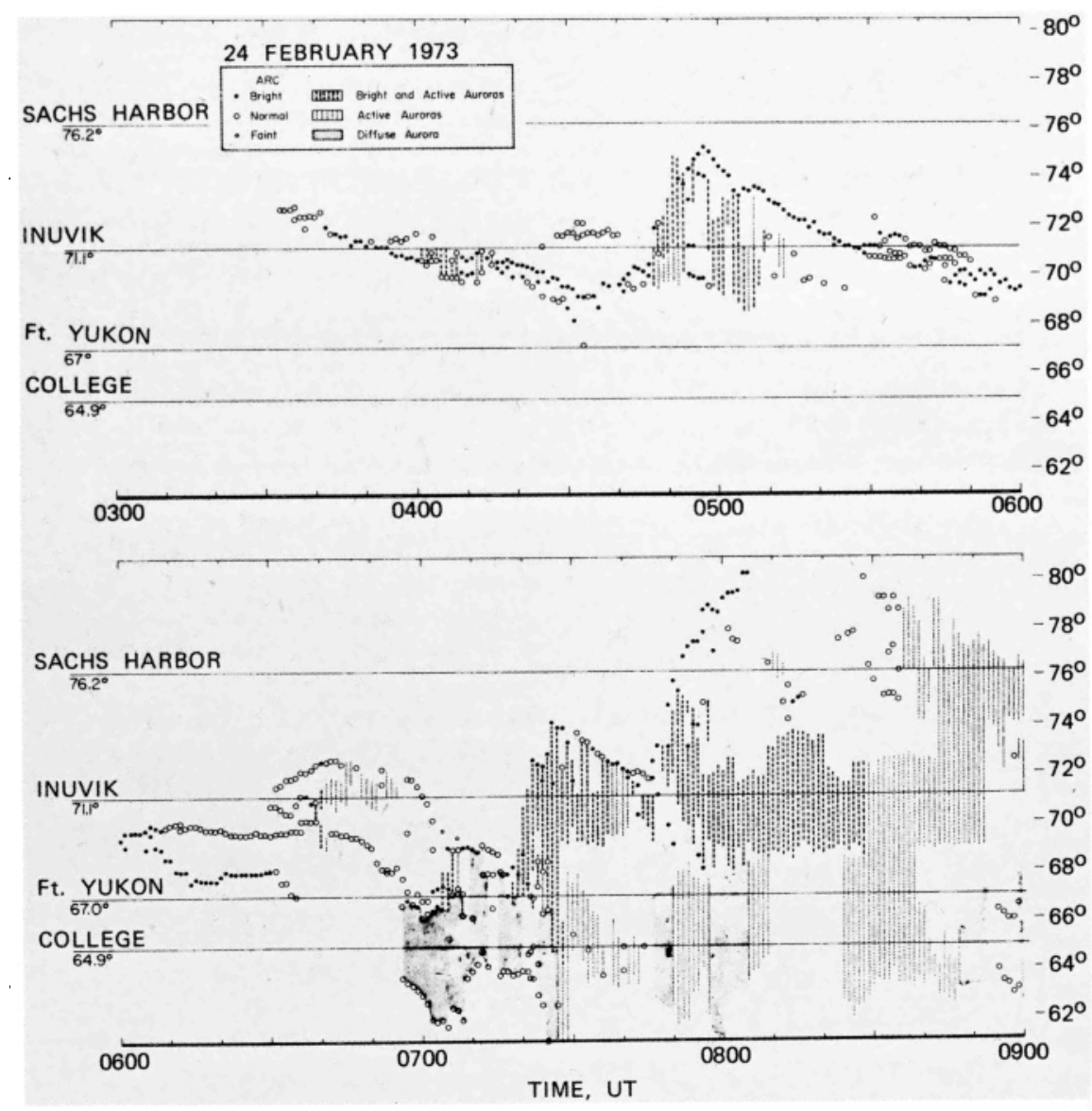

Fig. 3a. Summary of Alaska meridian chain all-sky camera data. 


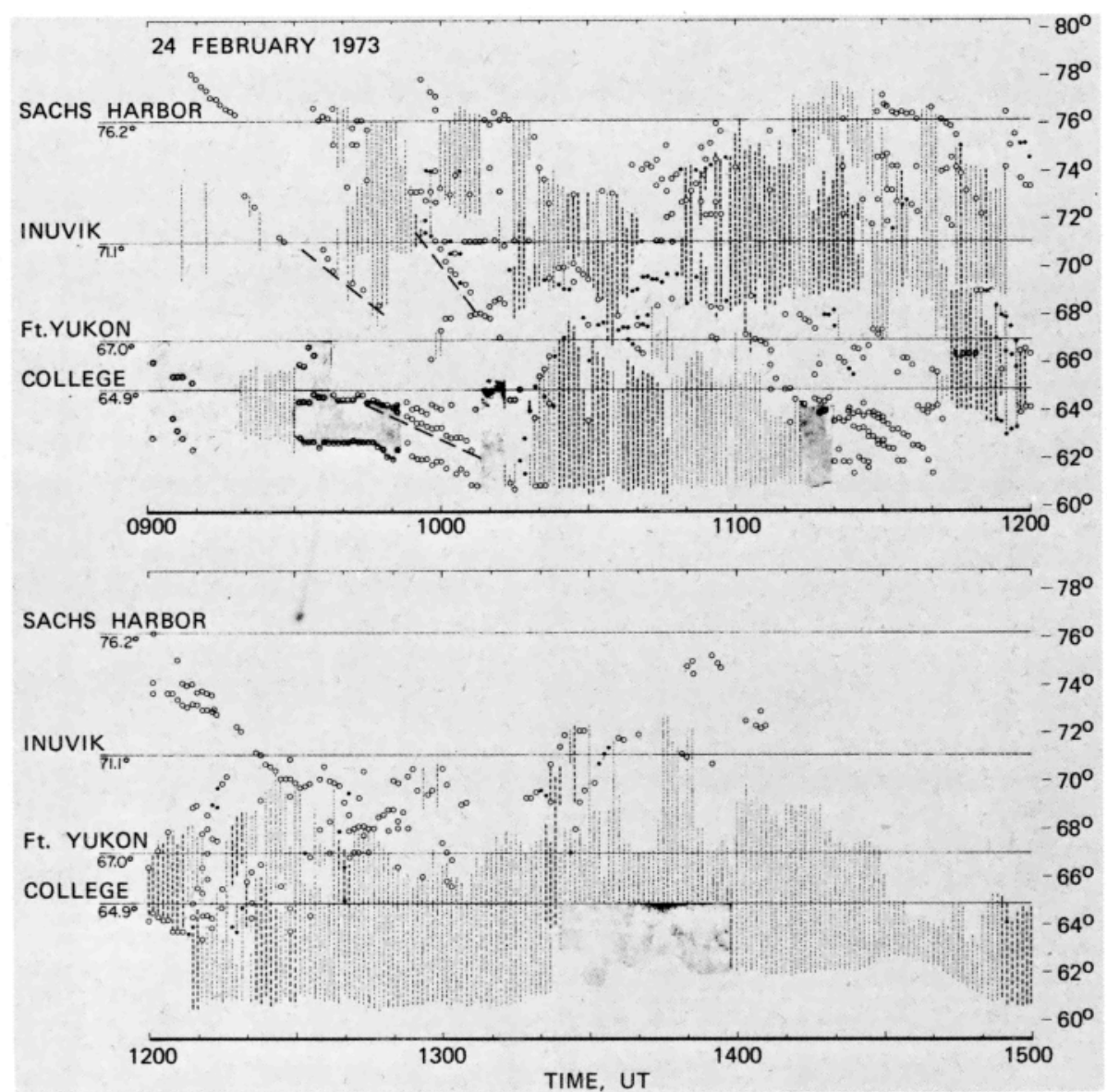

Fig. 3b. Summary of Alaska meridian chain all-sky camera data.

Alaskan meridian chain of all-sky cameras are summarized. The first general equatorward motion between 0330 and 0445 $\mathrm{UT}$ is associated with the daily motion of the meridian chain with respect to the auroral oval as described by Snyder and Akasofu [1972].

This pattern was interrupted at $0445 \mathrm{UT}$, when a surge passed over Inuvik. The College and Sitka magnetometer data showed positive $H$ bays at this time, whereas Meanook showed first a positive and then a negative excursion. The latter pattern has been identified with the passage of surges near or over the station [Akasofu and Kimball, 1964]. A general period of recovery prevailed until $\sim 0630 \mathrm{UT}$.

At $0630 \mathrm{UT}$, surgelike activity again spread rapidly over Inuvik, and the aurora began to move equatorward. The rate of equatorward expansion had increased sharply by 0650 UT. At $\sim 0658$ a diffuse luminosity appeared over College and shifted equatorward; it had a rather sharp southern boundary that looked like an arc. Lui et al. [1973] showed that such a feature is a typical appearance of the diffuse aurora. Discrete auroras near the northern edge of the diffuse region became active at that time and spread over College by 0720 UT.

Because the meridian chain was in the evening sector at this time, there are difficulties in identifying the onset time of the auroral substorm. However, a significant brightening of the arc visible above the northern horizon at College occurred at 0658 UT. Thus we tentatively infer that the onset time was at about 0658 UT or a few minutes earlier.

As was noted earlier, there was a weak surge activity 10-20 min before the substorm onset (Figure $3 a$ ). After the onset, at
0658 UT, a very intense surge spread over Inuvik (between b710 and 0725 UT). Recovery began around 0820 and continued until 1016 UT. Thus the beginning of the College negative $H$ bay at 0940 UT and the associated activity at Sitka prior to 1000 UT occurred during a period of recovery.

At $\sim 0945$ UT, two or more arcs (thus perhaps the diffuse aurora as described by Snyder and Akasofu [1972]) appeared to be formed slightly south of the zenith at College; they shifted rapidly equatorward until $\sim 1016 \mathrm{UT}$, when an arc to the south of College brightened and violently expanded poleward, this event indicating the onset of the second major substorm. The College all-sky photographs for this period are shown in Figure 4.

The magnetometer record from College indicates that the substorm intensification of the eastward electrojet achieved a maximum about 1030 UT and then began to subside. However, auroras were very active over a large latitude range, from dipole latitude $61^{\circ}$ to $77^{\circ}$; in particular, discrete auroras were extremely active over Inuvik between 1045 and 1130 UT. Thus the recovery in the magnetic record is only an apparent one, which was caused by the poleward shift of the center of the activity as the bulge expanded.

At $\sim 1120$ UT the center of activity again began to shift equatorward. Discrete auroras spread rapidly equatorward. At College a large loop developed around $1140 \mathrm{UT}$ and then gradually expanded in all directions while the central region of the loop periodically brightened considerably. The latitudinal extent of the activity began to contract at $\sim 1200$ UT. Active discrete auroral displays lasted until about 1300 UT. 


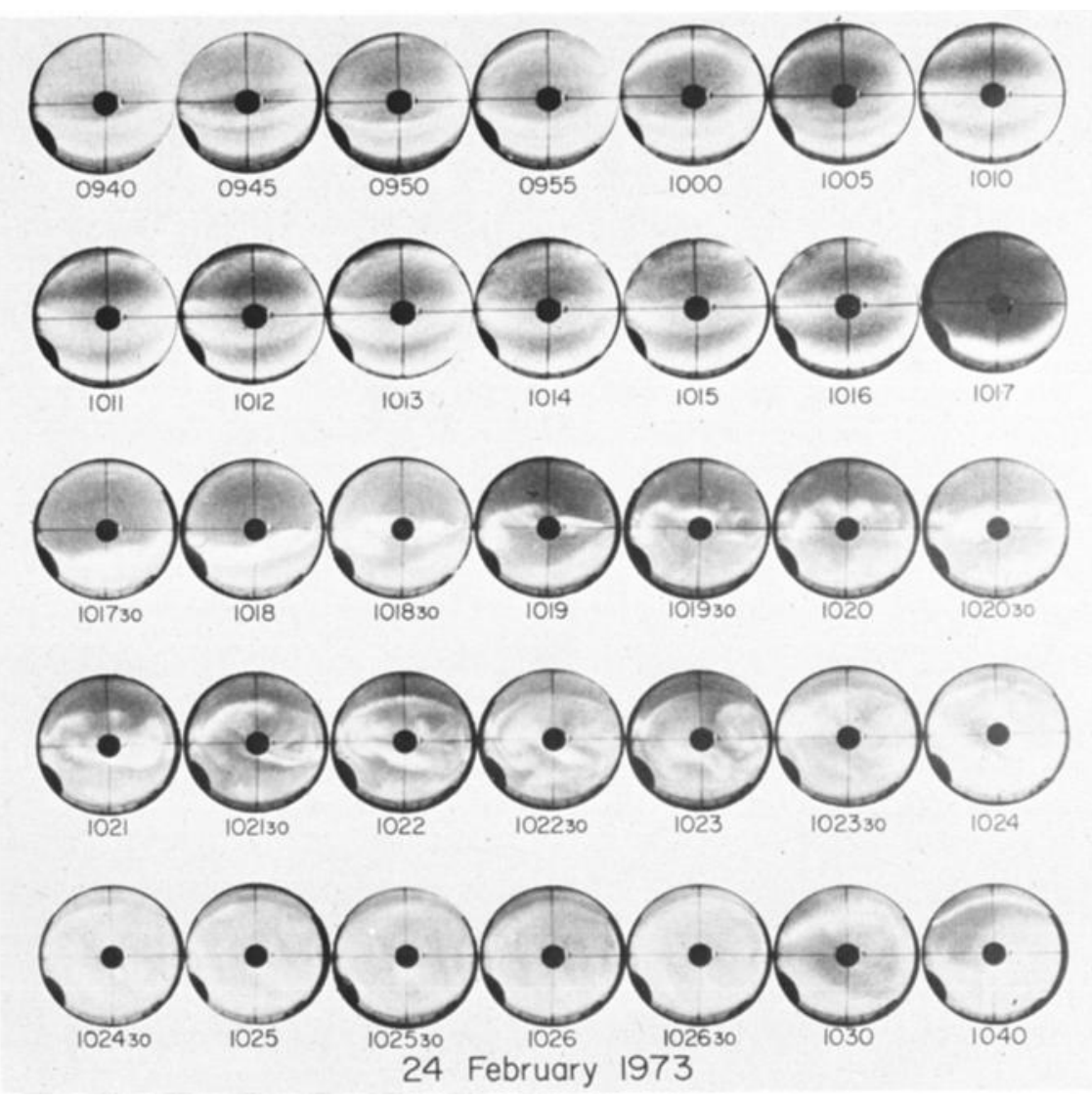

Fig. 4. College all-sky data in positive.

Between 1300 and 1305 UT, discrete auroras began to drift rapidly equatorward, then they disappeared, and the poleward boundary of the diffuse aurora became quite distinct. At 1313 UT a bright arc was formed between Fort Yukon and Inuvik, and it moved rapidly poleward. The diffuse aurora developed an $\Omega$ band structure that moved rapidly eastward [Akasofu and Kimball, 1964]. As is true for the evening sector, substorm onset time identification is difficult, but we tentatively identify a College morning sector substorm onset at 1313 UT.

In summary, we have identified three major auroral substorms that occurred during the evening of February 24, 1973. Each was preceded by a period of equatorward expansion of the auroral arcs as observed along the Alaskan meridian chain of all-sky camera stations. It is noteworthy that there are periods showing evidence of a large latitudinal gradient in the arc drift rate. This is shown by the dashed lines in Figure $3 b$. The entire evening was one of exceptional activity.

\section{Correlative Study}

The evening sector enhancement. In Figure 5 we show an expanded plot of $E_{E}$ for the period 0600 through 0900 UT together with the College magnetogram $H$ component. Superimposed on the figure are selected all-sky camera photographs (in negative) taken at Chatanika. In the photographs we have identified the $110-\mathrm{km}$ auroral altitude along the field line that intersects the $167-\mathrm{km}$ range gate, i.e., the foot of the flux tube. The point is near the Fort Yukon zenith.

We first note that $E_{E}$ began to recede from a positive value of $10-15 \mathrm{mV} / \mathrm{m}$ at $\sim 0650 \mathrm{UT}$, at which time the aurora over Inuvik began to drift rapidly equatorward (Figure $3 a$ ). Thus the first all-sky photograph shows an arc that had just appeared above the Chatanika northern horizon. The arc drifted steadily equatorward until $0658 \mathrm{UT}$, when it suddenly brightened.

By 0658 UT, the nominal onset time of the first substorm, $E_{E}$ had turned westward, and its magnitude continued to increase until it achieved a value of $-40 \mathrm{mV} / \mathrm{m}$ around $0740 \mathrm{UT}$. By 0810 UT the westward enhancement of $E_{E}$ had recovered to a mean value between -10 and $-15 \mathrm{mV} / \mathrm{m}$. The period of enhancement of $E_{E}$ coincided with the passage of an intense surge over College and an accompanying equatorward expansion of the auroral activity.

The magnitude of $E_{E}$ was considerably reduced for a brief period around $0720 \mathrm{UT}$ and for a somewhat longer period around 0800 UT. By examining the fifth all-sky photograph in Figure 5 we see that auroras within the measurement flux tube are bright and very active in comparison with those shown in the adjacent photographs numbered four and six. The cross in the all-sky photographs indicates the subfield line point at 110 $\mathrm{km}$ from the measurement altitude. We infer that there was a local precipitation-induced conductivity increase during this period.

The all-sky photographs through the 0800 UT period are shown in Figure 6. From 0756 through 0808 UT there were again bright active auroras within the measurement flux tube as identified by the cross in the photographs. Thus we interpret the brief but substantial reductions of the magnitude of $E_{E}$ as a shorting effect caused by local conductivity enhancements. The same effect has been observed by Mozer et al. [1973] as an anticorrelation between balloon-borne probe $E_{E}$ measurements and simultaneous $X$ ray data and has been 


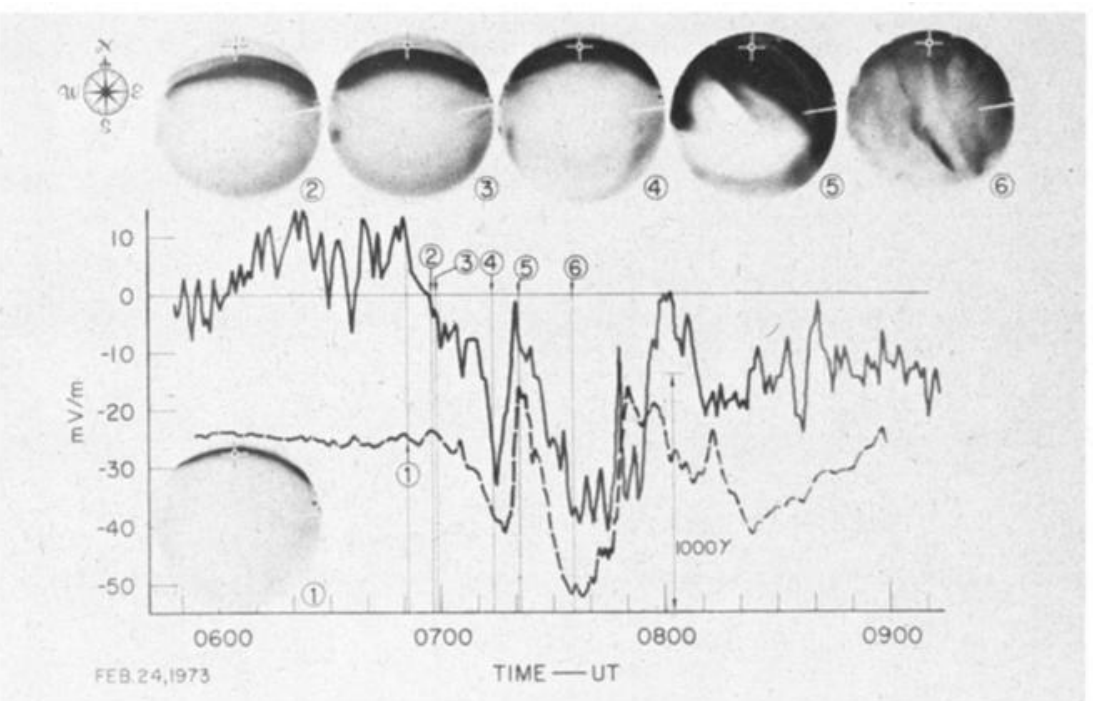

Fig. 5. Details of evening sector substorm (dashed line is College magnetometer $\boldsymbol{H}$ component records).

observed more directly with satellite particle detectors [Bogott and Mozer, 1971].

The midnight sector enhancement. In Figure 7 we have made a plot similar to Figure 5 for the period 0900-1100 UT. As is true for the evening sector enhancement, the midnight sector enhancement coincided with a period of accelerated equatorward motion of the auroras. This activity commenced at $\sim 0940$ UT. However, the westward enhancement of $E_{E}$ had subsided almost to its previous mean level of about -15 $\mathrm{mV} / \mathrm{m}$ by $1010 \mathrm{UT}$.

At 1016 UT the second major substorm of the evening occurred as indicated by the brightening of the arc on the southern horizon at Chatanika and its subsequent violent poleward expansion as shown in the fourth and fifth photographs. The only obvious $E_{E}$ effect during this period was the shorting that occurred when the expanding bulge reached the measurement flux tube at approximately 1025 UT. Evidently, the westward enhancement of $E_{E}$ subsided just before the substorm onset. From 1130 UT until dawn, active auroras were visible over the entire sky at College.

To summarize, first we have observed equatorward auroral motions prior to the onset of a major substorm. Such an effect has been observed by several workers [Pudovkin et al., 1968; Feldstein, 1972; Kelley et al., 1971; Mozer, 1971]. The effect is also discussed by Snyder and Akasofu [1972]. The radar data support the hypothesis that this motion is driven by an enhanced westward electric field. Second, there was an enhancement of the eastward electrojet beginning at 0940 as evidenced by the magnetometer data (cf. Figure 2).

The most intriguing question is whether or not these phenomena are manifestations of a substorm growth phase. From these data alone one cannot be certain. Our own interpretation is that the westward electric field enhancement is associated with an expansion of the auroral oval, possibly controlled by the interplanetary magnetic field as discussed by Akasofu et al. [1973] and Akasofu [1974]. A definitive answer must await additional data, in particular the interplanetary magnetic field data.

An intense postmidnight precipitation event and the morning sector enhancement. After the midnight sector substorm a bright loop developed around $1130 \mathrm{UT}$, and it slowly expanded until 1200 UT. The central portion of the loop occasionally brightened considerably. During these periods the auroral $E$ layer at $100-110 \mathrm{~km}$ increased in intensity by nearly 1 order of magnitude to $\sim 10^{12} \mathrm{el} / \mathrm{m}^{3}$.

This pattern of activity is shown in Figure 8 where we have plotted an expanded graph of the $1100-1300$ UT period, as shown in Figures 5 and 6. We first note that the development

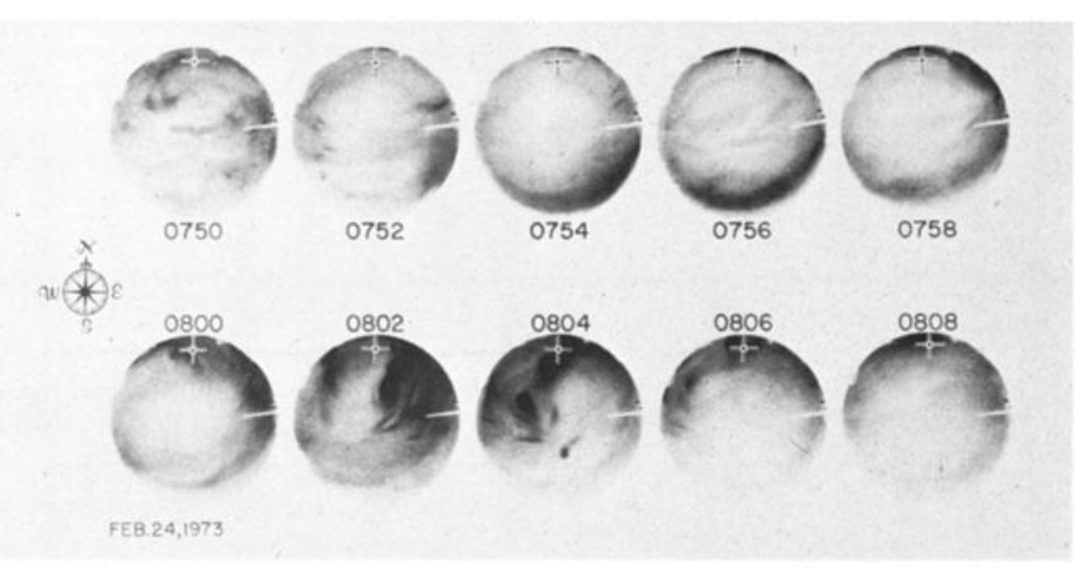

Fig. 6. Chatanika all-sky photographs in negative for the period through 0800 UT (dashed line is College magnetotneter $H$ component records). 


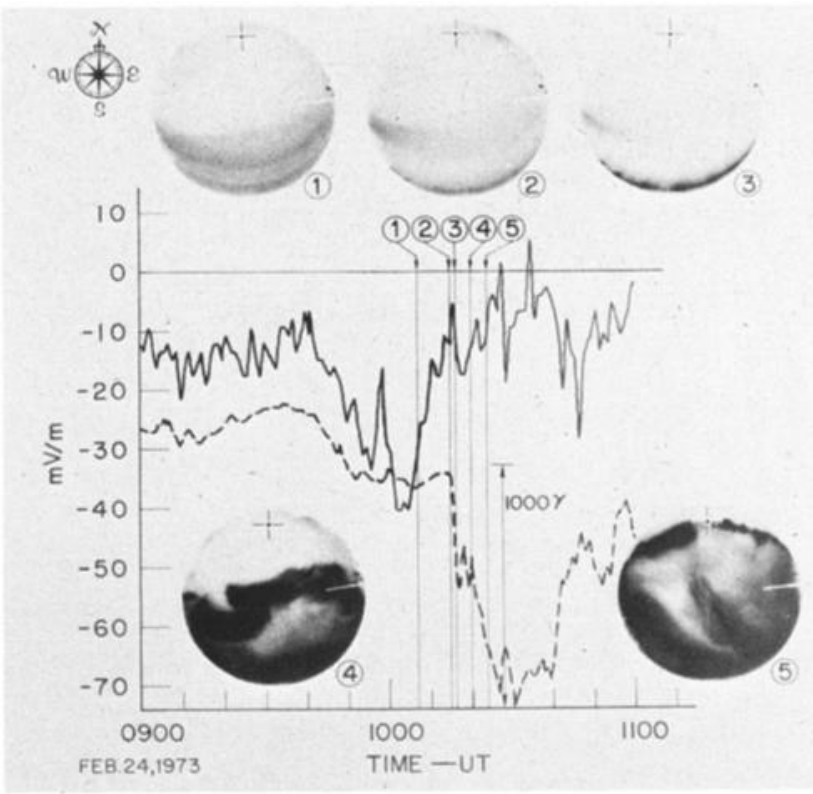

Fig. 7. Details of midnight sector substorm (dashed line is College magnetometer $\boldsymbol{H}$ component records).

of the westward field to approximately $-25 \mathrm{mV} / \mathrm{m}$ at $\sim 1110$ UT was accompanied by a general equatorward drift of the arcs over Fort Yukon and College (Figure $3 b$ ). Moreover, this pattern is quite similar to the one that occurred at $\sim 0940$ UT. Thus an enhanced westward field and an equatorward shift of the aurora need not always result in an auroral substorm.

We also note more evidence of shorting of the westward field during the periods around 1135 and 1150 UT that bracket the peak development of the westward electric field. The times coincide with the intensifications of the loop feature, as can be seen in the second and fourth all-sky photographs in Figure 8.

Moving on to $1300 \mathrm{UT}$, we see that, as is true for the evening sector enhancement, the morning sector enhancement coincided with an equatorward expansion of the aurora (cf. Figure $3 b$ ). Moreover, we have identified a substorm onset close to 1313 UT as discussed in the previous section. Thus the evening and morning sector enhancements display a remarkable degree of similarity with regard to their substorm relations. Again we note, however, that although these events fit the pattern of a substorm growth phase, the similar pattern that occurred at 1110 UT did not result in a substorm. Another example of the latter type will be described in the next section.

\section{Summary of Additional Meridian Plane Transport MEASUREMENTS}

The data of February 24, 1973, remain as the only evidence of pronounced substorm-related enhancements of a westwarddirected electric field component. This feature has not been in evidence during measurements made through less disturbed periods. However, the general pattern of an eastward-directed zonal field component southward of the instantaneous oval (perhaps in the region of the diffuse aurora) and a westwarddirected zonal component within the region of the discrete aurora seems to be a permanent feature. In this section we shall present additional data that support the conclusions reached in the previous section.

Results for February 17, 1973. A 5-hour series of geomagnetic meridian plane drift measurements was made on
February 17, 1973, from 0500 through 1000 UT. A weak positive $H$ bay developed at College, Alaska, starting at approximately $0530 \mathrm{UT}$, achieving a peak value of $\sim 30 \gamma$ at 0730 UT, and subsiding by 0930 UT. The Fort Yukon all-sky camera data show that the auroras were well to the north of the radar except for the equatorwardmost arc, which was visible above the horizon at Chatanika by 0600 UT. A weak surge passed to the north of the Fort Yukon zenith from approximately 0629 through $0700 \mathrm{UT}$. By $0711 \mathrm{UT}$, no auroras were visible at Chatanika.

The radar data together with the College magnetogram $D$ trace are shown in Figure 9. The zonal field was generally eastward from $0600 \mathrm{UT}$ until just before $0700 \mathrm{UT}$, when it switched abruptly westward. The College magnetogram $D$ trace shows a coincident reversal. We interpret this event as an equatorward expansion of a region of a generally westward zonal field.

To support this interpretation further, we note that for the shaded portions of the radar data in Figure 9 the antenna was pointed southward in the geomagnetic meridian plane at an elevation of $45^{\circ}$. Thus the inferred zonal fields correspond to a region approximately $200 \mathrm{~km}$ southward of the corresponding region for the unshaded data. We see that the zonal field initially remained eastward-directed, even though it achieved a value of $20 \mathrm{mV} / \mathrm{m}$ westward $200 \mathrm{~km}$ to the north. When the activity subsided, the large latitudinal gradient was not in evidence, as can be seen from the data taken from 0800 to 1000 UT.

Now, so far we have only discussed transport measurements from a range gate centered at $167 \mathrm{~km}$. The radar, of course, measures electron densities at all ranges. In Figure 10 we have plotted density profiles as a function of height for the times indicated between 0600 and 0615 UT. As was discussed in paper 1 , because of the geometry of the measurement, height and latitude increase simultaneously. Thus, for example, the returns at $250 \mathrm{~km}$ are coming from a region to the north of the returns at $200 \mathrm{~km}$.

With this in mind we note in Figures $10 a$ and $10 b$ the density enhancement between 200 and $300 \mathrm{~km}$. This feature is a moving wall of ionization of the same type as the ionization

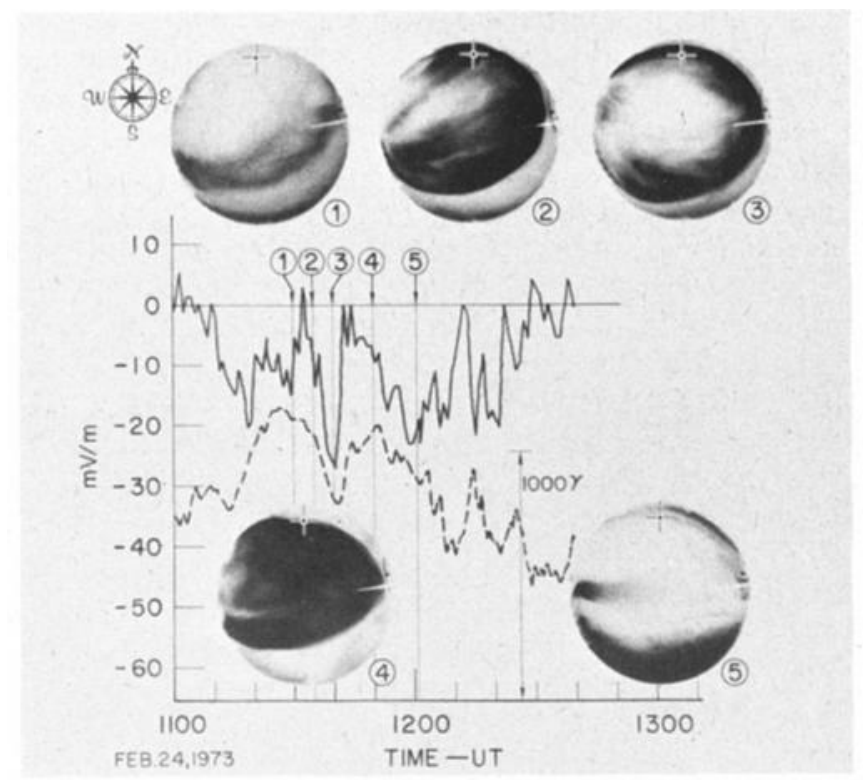

Fig. 8. Details of postmidnight precipitation event. 


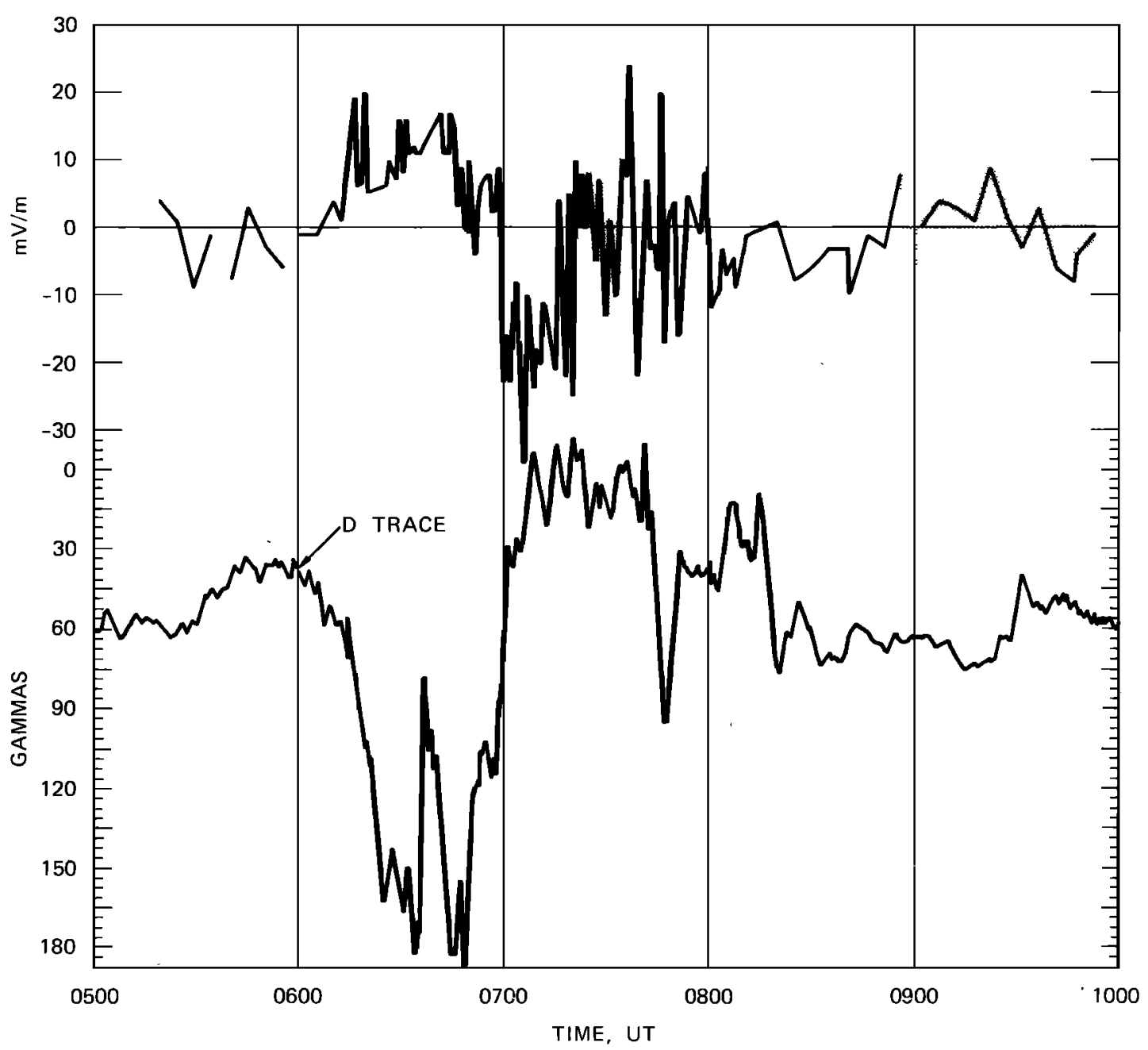

Fig. 9. Eastward electric field data of February 17, 1973.

patches discussed extensively in paper 1 . The drift rate for the first two frames is nearly $200 \mathrm{~m} / \mathrm{s}$ equatorward. However, by 0612 , when the peak reached approximately $220 \mathrm{~km}$, the drift ceased (see Figures $10 c-10 f$ ).

In paper 1 it was shown that such patches or zones of ionization drift equatorward with the convection velocity. Thus we can infer that well to the north of the radar the zonal field was westward-directed, reduced to nearly zero just north of the Fort Yukon zenith, and finally turned eastward in the region where the radar measurements were made. We also note the rapid enhancement of the $E$ layer near $110 \mathrm{~km}$, coincident with the eastward excursion of the College magnetometer $D$ trace.

Results for February 18, 1973. On February 18, 1973, a second set of meridian plane measurements were made from 0700 to 1200 UT. The evening was quiet until before 0900 UT, when a positive $H$ bay began to develop at College. The radar was operated alternating between northward-looking and southward-looking measurements from 0700 until 1000 UT, when it was held fixed looking northward.

The zonal field reversed direction from eastward to westward shortly after 0800 UT as the positive bay began to develop. The westward-directed zonal field steadily increased in magnitude, and a north-south gradient was clearly evident. The radar data for the period when the antenna was fixed are shown in Figure 11. During this period a large loop developed and drifted slowly westward. The previously discussed 'short- ing' phenomenon is evident as the edge of the loop drifted through the measurement flux tube.

Almost immediately after the radar data stopped, a negative bay developed at College, indicating a substorm onset. It was not preceded by any obvious enhancement of the westwarddirected zonal field component, as was seen in the February 24,1973 , data.

Additional meridian plane data were taken on February 19 and 21,1973 . These nights were generally very quiet. The zonal field component was small $(<10 \mathrm{mV} / \mathrm{m})$ and generally eastward-directed throughout the measurement periods. These small field values are, however, uncertain because of confusion with parallel drifts.

\section{Concluding Remarks}

In this paper we have shown evidence of a zonal electric field boundary located somewhere in the vicinity of the poleward boundary of the diffuse aurora, which itself is usually near or within the region of the discrete aurora. During the very active period of February 24, 1973, the boundary was distinctly identified with the equatorwardmost discrete auroral arc. For the less disturbed periods the location of the boundary with respect to the aurora was not so well defined.

From the radar data alone, it is not possible to discriminate between moving but quasi-rigid spatial patterns and temporally varying fields. We have inferred the presence of a 
quasi-rigid spatial pattern from the relation between the field reversals and the location of the aurora and in one case from the behavior of moving patches of ionization.

Finally, we observed three intense substorms on February 24,1973 , that were preceded by equatorward shifts of the discrete aurora and coincident enhancements of westward field component. However, there were two occasions (on February 17 and 24, respectively) in which a similar enhancement of the westward electric field did not lead to the onset of the expansive phase of substorms.

Since we have shown that the westward electric field is present in the belt of discrete auroras and the eastward field a little equatorward of it, the radar (a fixed point) observed an apparent change of the direction or an apparent enhancement as the auroral oval shifts across the subfield line point as well as changes and enhancements.
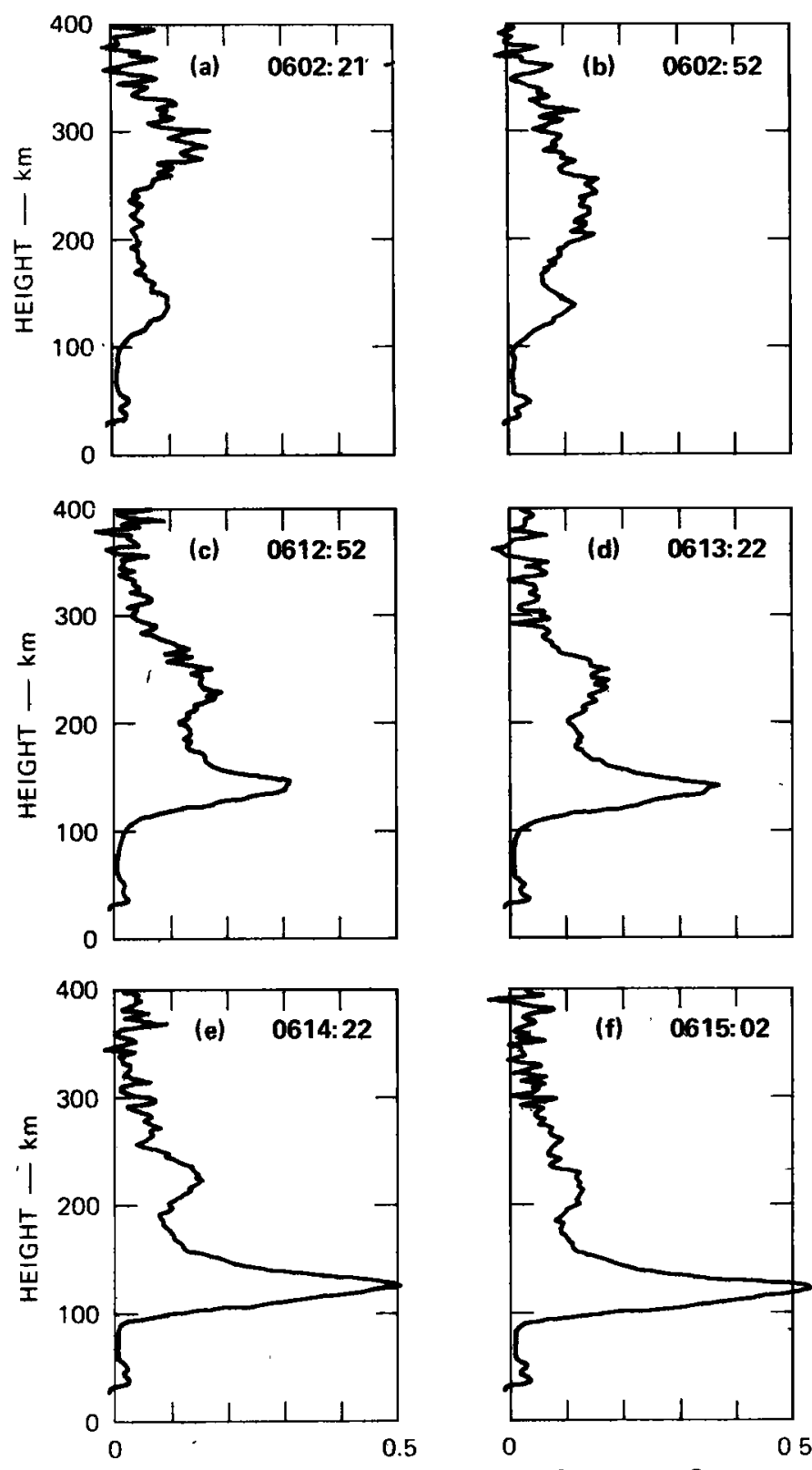

ELECTRON DENSITY $\times 10^{6} \ldots \mathrm{el} / \mathrm{cm}^{2}$

Fig. 10. Electron density profiles of February 17, 1973 (azimuth, $23^{\circ}$; elevation, $45.7^{\circ}$ ).

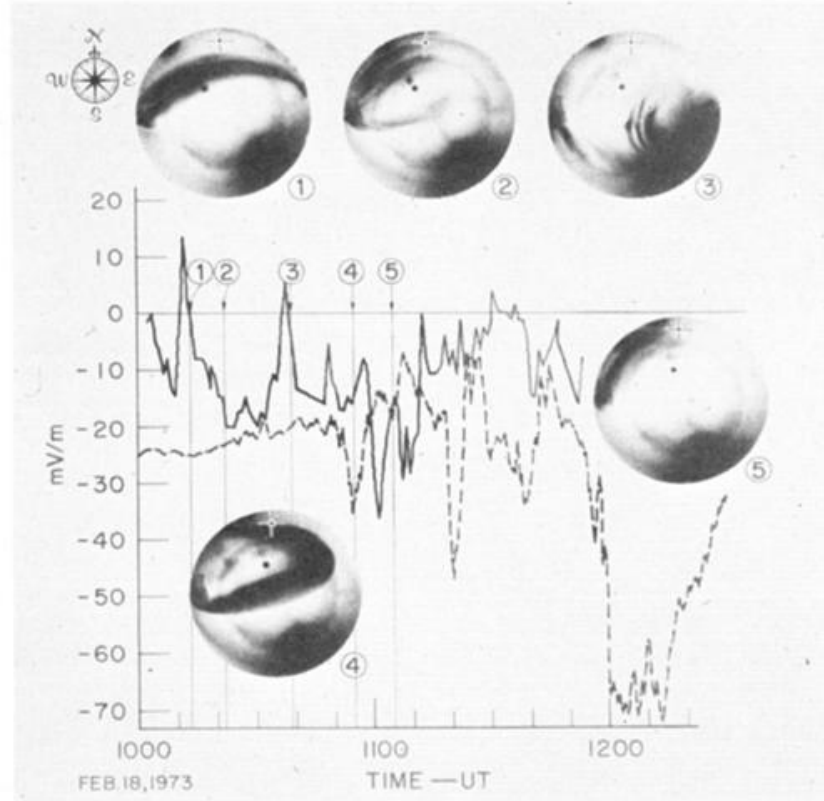

Fig. 11. Eastward field data for February 18, 1973.

Thus our result can be interpreted as follows: some substorms occur after the equatorward expansion of the oval and some occur without being preceded by the expansion (that is, substorms along the contracted oval). This interpretation is consistent with the results obtained by Akasofu et al. [1973], who concluded further that the oval expansion is not the necessary condition for substorms and that it is unlikely to be a growth phase feature.

Acknowledgments. The assistance of J. Hodges of Stanford Research Institute in performing these experiments is gratefully acknowledged. Part of this work was performed while one of the authors (P. M. Banks) was on sabbatical leave of absence at the Stanford University. This work was supported in part through DNA contract DNA001-72-C-0076 and NSF grant GA 36095 at Stanford Research Institute and through grants NSF GA-30351 and NASA NGR-05-009-075 at the University of California, San Diego. The Alaska meridian chain was operated under the National Science Foundation, Atmosphere Sciences section, grant GA-37094. We would like to thank John Teas for his effort in the operation.

The Editor thanks T. N. Davis and J. V. Evans for their assistance in evaluating this paper.

\section{REFERENCES}

Akasofu, S.-I., The aurora and the magnetosphere; the Chapman Memorial Lecture, Planet. Space Sci., in press, 1974.

Akasofu, S.-I., and D. S. Kimball, The dynamics of the aurora, 1, Instabilities of the aurora, J. Atmos. Terr. Phys., 26, 205, 1964.

Akasofu, S.-I., P. D. Perreault, F. Yasuhara, and C. I. Meng, Aurora substorms and the interplanetary magnetic field, J. Geophys. Res. $78,7490,1973$.

Banks, P. M., C. L. Rino, and V. B. Wickwar, Incoherent scatter radar observations of westward electric fields and plasma densities in the auroral ionosphere, 1, J. Geophys. Res., 79, 1887, 1974.

Bogott, F. H., and F. S. Mozer, Equatorial proton and electron angular distributions in the loss cone and at large angles, $J$ Geophys. Res.; 76, 6790, 1971.

Coroniti, F. V., and C. F. Kennel, Changes in magnetospheric configuration during the substorm growth phase, J. Geophys. Res., 77 , $3361,1972$.

Feldstein, Y. I., Auroras and associated phenomena, in Solar- 
Terrestrial Physics/1970, edited by E. R. Dyer, p. 152, D. Reidel, Dordrecht, Netherlands, 1972.

Kelly, M. C., J. A. Starr, and F. S. Mozer, Relationship between magnetospheric electric fields and the motion of auroral forms, $J$. Geophys. Res., 76, 5269, 1971.

Lui, A. T. Y., P. Perreault, S.-I. Akasofu, and C. D. Anger, The diffuse aurora, Planet. Space Sci., 21, 857, 1973.

McPherron, R. C., C. T. Russell, and M. P. Aubry, Satellite studies of magnetospheric substorms on August 15, 1968, 9, Phenomenological model for substorms, J. Geophys. Res., 78, 3131, 1973.

Mozer, F. S., Origin and effects of electric fields during isolated magnetospheric substorms, J. Geophys. Res., 76, 7595, 1971.

Mozer, F. S., F. H. Bogott, and B. Tsurutani, Relations between ionospheric electric fields and energetic trapped and precipitating electrons, J. Geophys. Res., 78, 630, 1973.

Pudovkin, M. I., O. I. Shumilov, and S. A. Zaitseva, Dynamics of the zone of corpuscular precipitations, Planet. Space Sci., 16, 881, 1968.

Snyder, A. L., and S.-I. Akasofu, Observations of the auroral oval by the Alaskan meridian chain of stations, J. Geophys. Res, 77, 3419, 1972.

Vasyliunas, V. M., and R. A. Wolf, Magnetospheric substorms, some problems and controversies, Rev. Geophys. Space Phys., II, 181, 1973.

(Received April 4, 1974;

accepted July 22, 1974.) 